\title{
Land Use and Land Cover Changes of West Tahta Region, Sohag Governorate, Upper Egypt
}

\author{
Ismail Esam $^{1,2}$, Faid Abdalla ${ }^{3}$, Niesner Erich ${ }^{1}$ \\ ${ }^{1}$ Department of Applied Geosciences and Geophysics, Montanuniversität Leoben, Leoben, Austria \\ ${ }^{2}$ Geology Department, Faculty of Science, Minia University, El-Minia, Egypt \\ ${ }^{3}$ National Authority for Remote Sensing and Space Sciences (NARSS), Cairo, Egypt \\ Email: esamismail79@yahoo.com
}

Received October 1, 2012; revised November 2, 2012; accepted December 5, 2012

\begin{abstract}
Due to the growing of population in Egypt during the last few decades, great changes in agricultural area, and urbanization of Egypt art occurred. In this study we utilized the available record of multitemporal Land sat Thematic Mapper (Tm) and Egypt sat image to produce land cover/land use map of the area between 1987 and 2009. Also we used the post-classification change detection analysis to detect the change in the agriculture, urban areas and the change in the River Nile during the period between 1987 and 2009. The post-classification change detection analysis shows that agriculture development increased by 1785.96 Hectare through the study period with average annual rate of land reclamation 81.18 Hectare/year. While the urban area increased by 2231.24 Hectare with average annual rate 101.42 Hectare/ year the increase of the urbanization and the growth occurring through encroachment into the farmer old cultivated lands. The change in the River Nile is not so much is reached to 138.32 Hectare in the study period with average annual rate 6.29 Hectare/year. The result of this study show that, the accuracy are quantify with the land cover changes and also delineate their spatial patterns, which display the efficiency of land sat in evaluating landscape dynamics over a particular time span. This data are very useful for natural resources management.
\end{abstract}

Keywords: Land Use; Land Cover; Remote Sensing; Change Detection

\section{Introduction}

Egypt is one of the lands which suffering from the rabid growth of population, the total population increased ranged from 11 million in year 1907 to 79.88 million in 2011 [1]. This increase leads to all the people which are live neighbor the River Nile in the past to search about anew area to live in it. [2] noticed that the Quaternary River Nile sediments which occupy 5\% of the Egypt area support $90 \%$ of Egypt's agriculture production. In the last three decades the development of the Egyptian desert has accelerated rapidly for reliving overpopulation pressure in the narrow Nile Valley and Delta which the average annual growth rate is expected to reach $1.75 \%$ [3]. The successive governments of Egypt adopted policies seeking self sufficiency in food production through the extension of cultivated land (1.2\% per year) and maximization of production of the existing agricultural land [4]. Also the national plan aims at exploiting $25 \%$ of the territory of Egypt by the end of the first half of the 21st. Reclamations for agriculture purposes and human settlements have targeted different areas throughout the Egypt and the southern part of the western desert are which the study area lie in it is a part of these areas.
The study area is lies in the western side of the River Nile at Tahta in the Sohage governorate, Upper Egypt. Upper Egypt becomes important and attractive area after the national project of agriculture (Tushka). Remote sensing studies are applied to monitoring and evaluate the change and the development of these new areas. Remote sensing data provide the better source for derivations of land-use due to reproducibility, internal consistency and coverage in locations where ground-based knowledge is sparse $[5,6]$. Remote sensing technology has greatly facilitated investigation and monitoring of land use/cover changes. Several factors such as image quality, data analysis methodology, interpretation techniques, and numerous temporal and phonological considerations became known to significantly influence the quality of the resulting geospatial information [7]. Land sat Thematic Mapper (TM) and Enhanced Thematic Mapper Plus $(\mathrm{ETM}+)$ data have been widely applied in for land-use and change detections studies [8-10].

The accuracy of the resulting change maps is subjected to error propagation and is dependent on the accuracy of the input classification maps, the individual classified images constitute a historical series that can be used in 
applications other than change detection [11].

In this study the change detection application using post classification comparison along with field investigations were used to detect the change in agriculture areas, urban areas, and River Nile during the period from 1987 to 2009 of the area under investigation. The quality of the land-use maps and change detection information produced were ensured through accuracy assessment analysis. The validated change detection results facilitated comparing vegetation cover patterns and urban land-use trends and the River Nile change are spatially and quantitatively. The information gleaned from land-use/cover and changes over time can be used in formulating management policies of the national governments and monitoring active agricultural programs.

\section{Materials and Methods}

Landsat Thematic Mapper (TM) acquired in 1987 (Figure 1) and Egypt sat 2009 (Figure 2) have been used to detect the change in agriculture and urban areas as well as the River Nile, from 1987 to 2009. The topographic maps prepared by the Egyptian Military Survey at scale 1:50,000 were also used as well as field investigations. Numerous change detection methods have been developed to assess variations in the land cover using satellite data including image differencing, principal component method and post-classification comparisons. Among these techniques the post-classification comparison is preferable. The accuracy of this technique to detect the dynamic changes depends mainly on the accuracy of the individual classification of each land cover unit.

In this study radiometric calibration was performed using ERDAS imagine -9.2 [12]. Geometric correction is applied to raw sensors data to correct errors of perspective due to the Earth's curvature and sensor motion. Some of these errors are commonly removed at the sensor's data processing center (NASA). Georeferencing refers to the process of assigning map coordinates to image data. Image mask process is used to reduce consumed time during processing and the storage capacity of processed images [13].

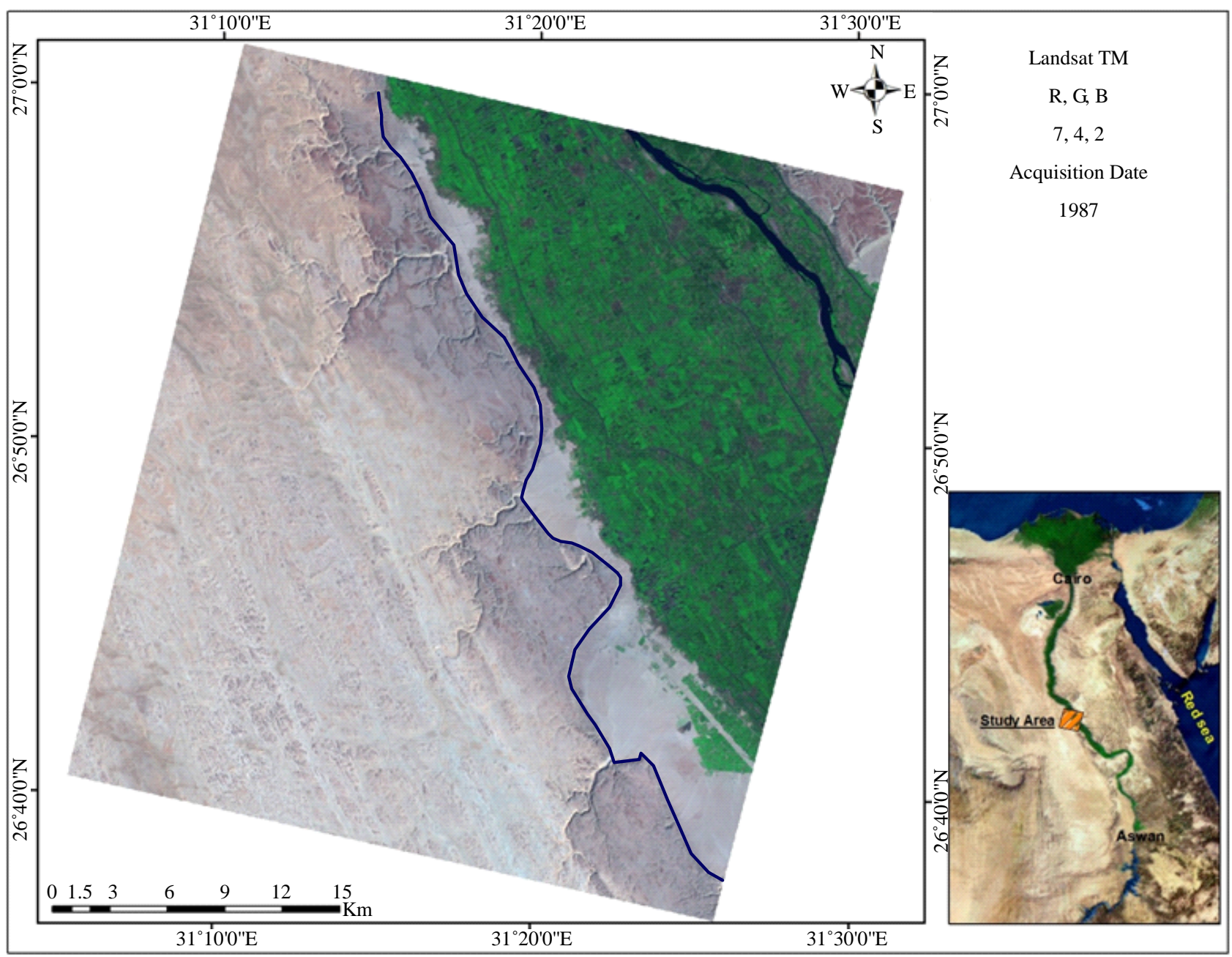

Figure 1. Land sat TM acquired in 1987 (blue line is scarp border). 


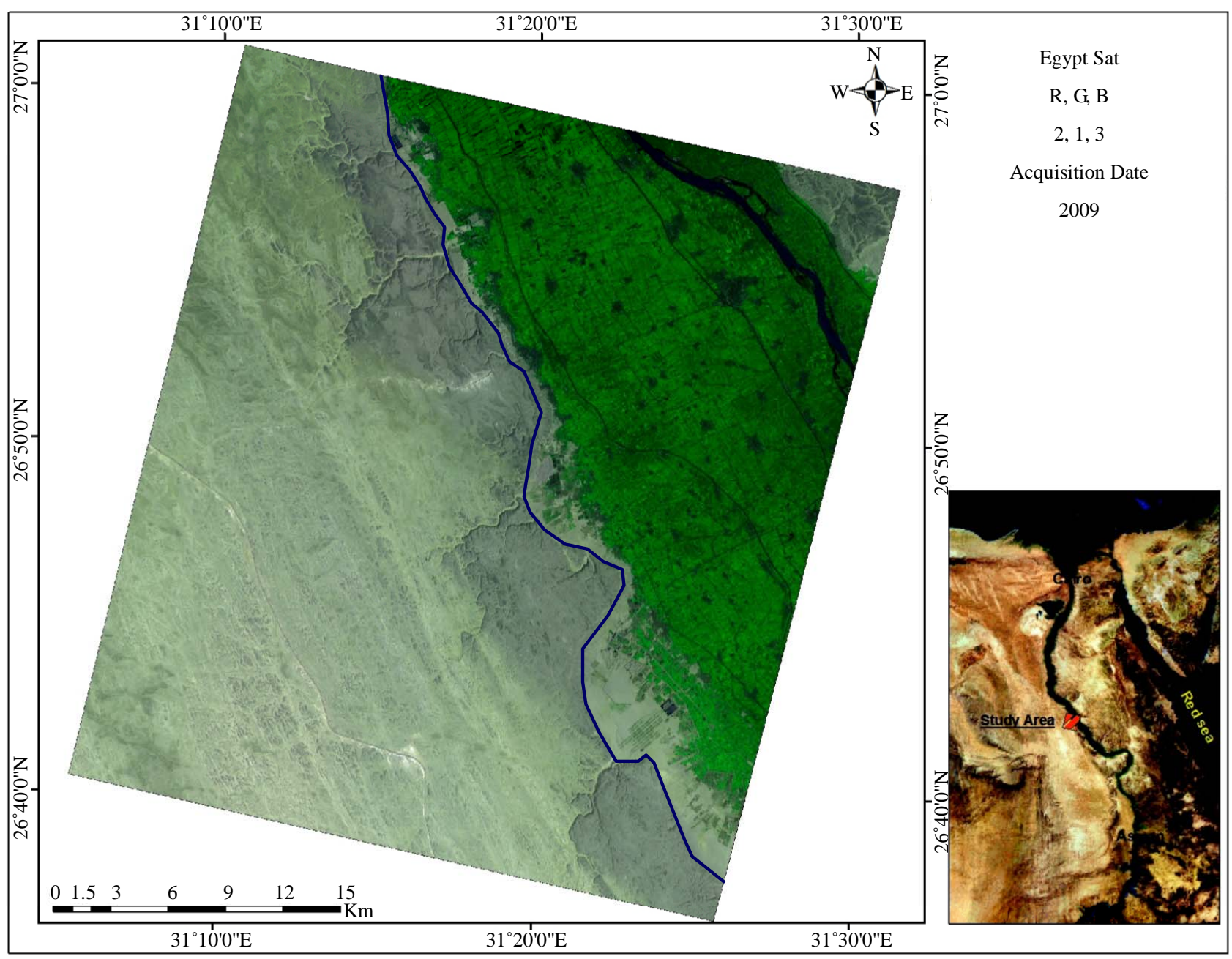

Figure 2. Egypt sat 2009 (blue line is the scarp border).

Multispectral image classification is used to extract thematic information from satellite images in a semiautomatic way [14]. Digital image classification uses the spectral information represented by the digital numbers in one or more spectral bands and attempts to classify each individual pixel based on the spectral information. This type of classification is termed spectral pattern recognition. The result of classified image is comprised of a mosaic of pixels, each of which belongs to a particular theme and essentially a thematic "map" of the original image.

\section{Image Classification}

In this study the TM data and Egypt sat data were classified by using supervised and unsupervised classification technique.

Supervised classification has been developed for satellite image processing where it has been applied to the classification of spectral layers. Supervised classification depends mainly on the experience and accuracy of the user in detecting the signature differences between various units in the satellite image using his naked eyes. Using ERDAS Imagine version 9.1 new supervised classification analyses were carried out on the TM (1987) and Egypt sat (2009) images to identify the land use/cover changes in the study area. The supervised classification wasn't able to differentiate between various landcover units, so the unsupervised classification technique took place which gave more valuable and accurate results.

In the unsupervised classification, the computer separates the pixels into classes with no directions from the analyst [15]. This means that unsupervised classification techniques do not require the user to specify any information about the features contained in the images. In the study area the unsupervised classification applied to the six visible and reflected IR bands of the subscene resulted in 20 classes. At this point, the image is difficult to interpret. Decisions need to be made concerning land cover types corresponding to each category.

To make these decisions, additional materials and knowledge of the area are useful. Checking in the field, 
the various areas discriminated in the digital image should be performed at the time of correction of the image to obtain more accurate results. If this knowledge is not available, scientific reasoning may be used to group the various categories together into related land cover units. In the case of the present study the second option was the only possibility. The unsupervised classification analyses (Figures 3 and 4) were carried out on the TM (1987) and Egypt sat (2009) images to identify the land use/cover changes in the study area. Three different land use classes were identified which include the following:

1) Agriculture and cultivated lands with the green color.

2) Urban and man made structures with the black color.

3) River Nile with the blue color.

Post-classification refinement was used to improve the accuracy of the classification as it is a simple and effective method [16], because urban surface is heterogeneous and composed of a complex combination of features (e.g., buildings, roads, grass, trees, soil, water) [17]. After the performance of the post-classification refinement, the misclassifications have been mostly corrected. The postclassification transformation of the classified raster into shape three vectors has been done using ENVI version 4.5 and using ARC GIS tool. The obtained shape three was converted into a geodata base in order to introduce the change detection analysis. Before this step, it is necessary to make sure that the classification used for the change detection procedure is matching fact in the field using the accuracy assessment technique.

\section{Accuracy Assessment}

Accuracy is the degree of closeness of results to the true values. The expected accuracy and the level of confidences obtained from a particular accuracy assessment approach depends primary on the number of samples of each class and the quality of reference data set involved in the analysis. The classified thematic maps are produced for a wide variety of resources: soil types or properties, land cover, land use and many more. These maps

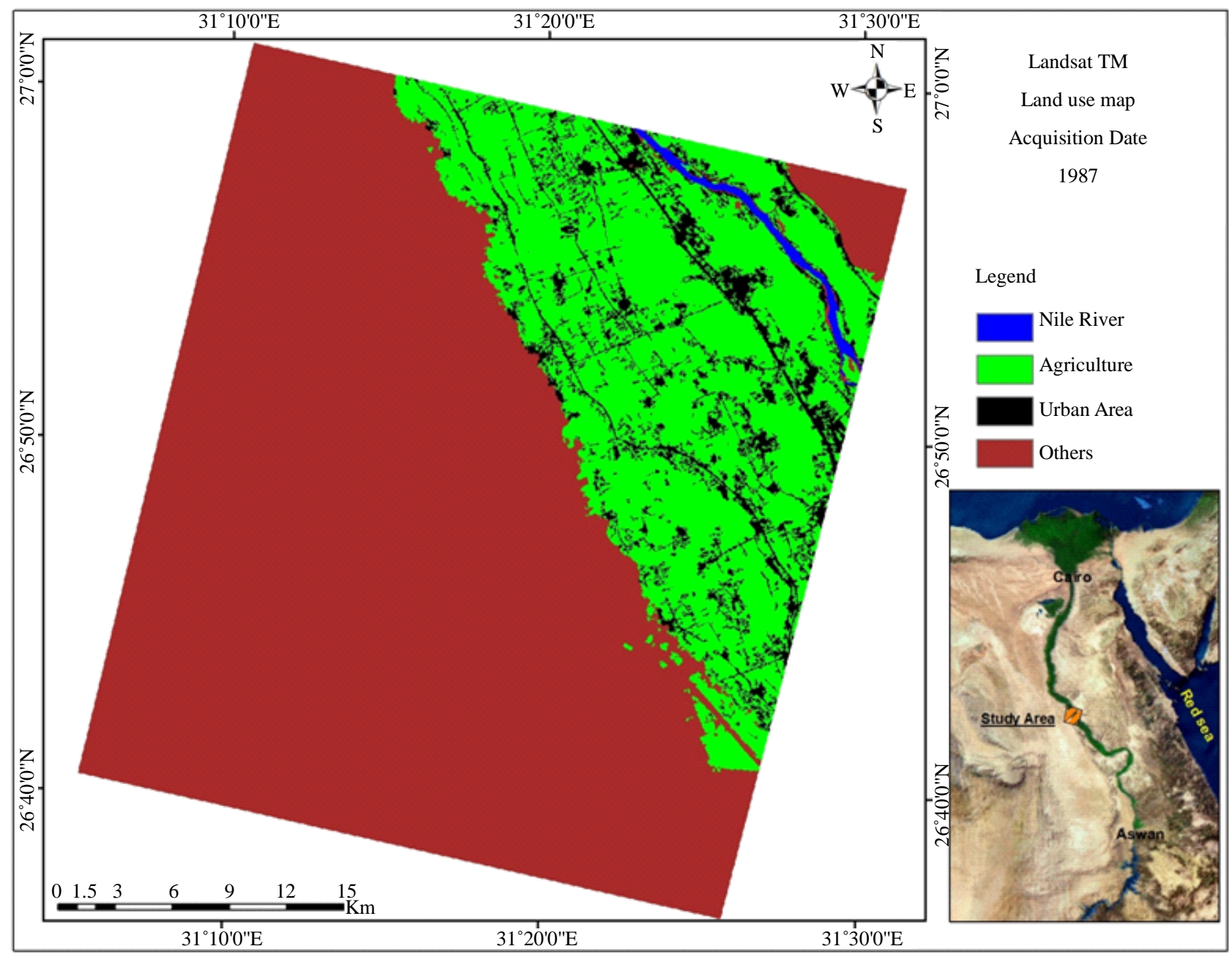

Figure 3. Land use map 1987. 


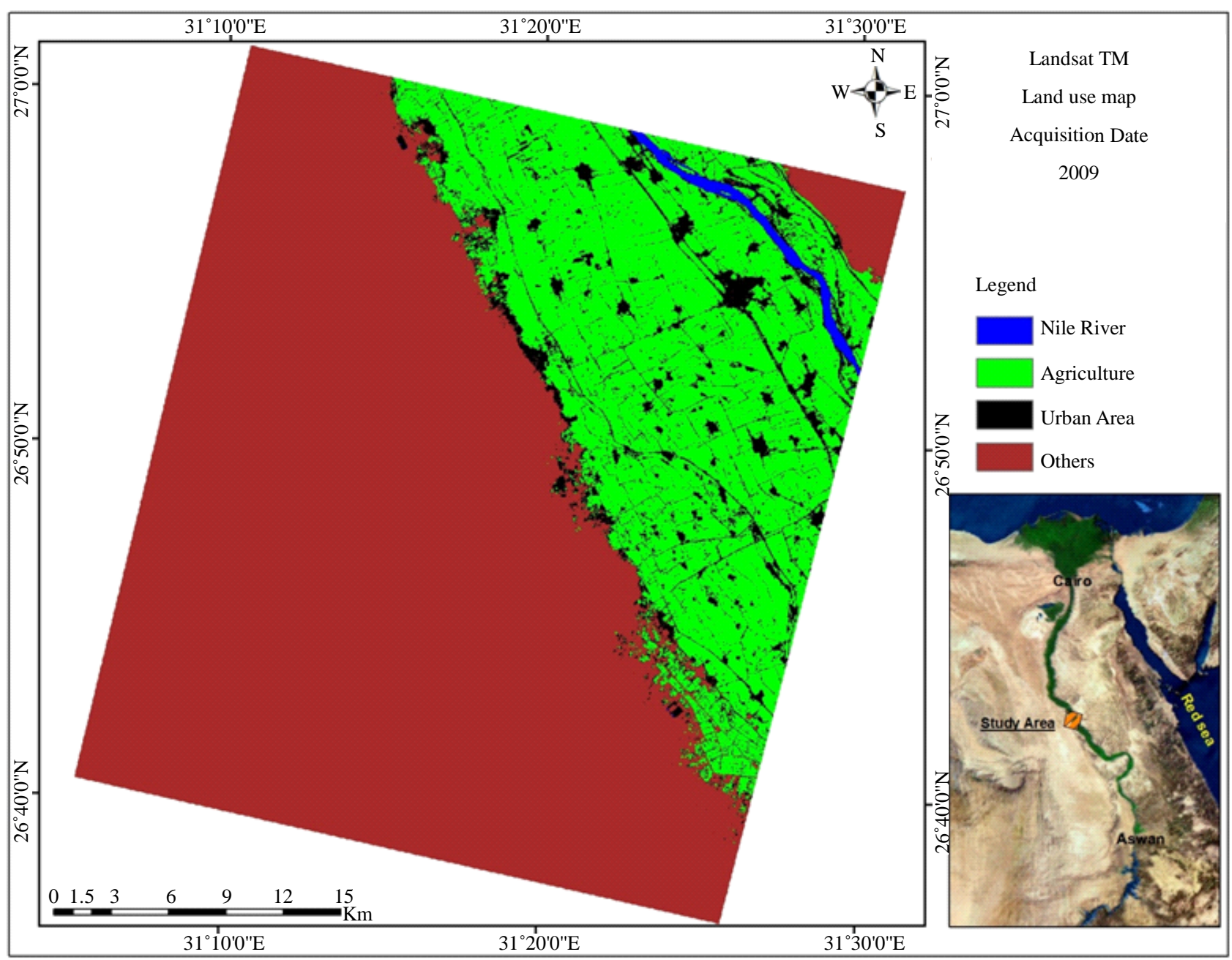

Figure 4. Land use map 2009.

are not very useful without quantitative statements about their accuracy. Generally, classification accuracy refers to the extent of correspondence between the remotely sensed data and reference information [17].

The accuracy of digital land cover classifications can be expressed quantitatively by building and interpreting a classification error matrix. An error matrix compares information from a classified image or land cover map to known reference ("truth") sites for a number of sample points.

The accuracy assessment of the land cover maps extracted from Landsat data include the generation of 100 random references ("truth points") for each land cover map. Accuracy assessment of the land cover maps after the post-classification refinement and merging of the 20 classes into 3 classes covering the major land cover units was then performed using field data, topographic maps, and the results were recorded in a confusion matrix. Confusion matrix, standard method for accuracy assessment [18-20] is applied to detect the accuracy of both classification and change detection outputs. Two impor- tant information can be derived from the error matrix: errors of omission, or producer's accuracy, and commission, or user's accuracy [21-23]. The user's accuracy of a specific class is the ratio of the correctly classified samples to the total number of samples selected in that class. A Kappa coefficient is commonly used as a measure of the map accuracy [20,24]. Typically, the overall accuracy target of $85 \%$ with no class less than $70 \%$ accuracy is acceptable for land-use/land-cover mapping with Land sat data $[25,26]$. The accuracy of the land-use/landcover maps was evaluated at several stages in the processing. [27] found that integrating visual interpretation with supervised classification increase the overall accuracy by about 10 percent in areas undergone a severe land-cover change. The expected accuracy and the level of confidence obtained from a particular accuracy assessment approach depend primarily on the number of samples of each class and the quality of reference data set involved in the analysis. The accuracy of both classification and change detection outputs in terms of agreement between our derived map and references datasets is evaluated empirically 
using confusion matrices, standard method for accuracy assessment $[18,20]$. Important information can be derived from the errors of omission, or producer's accuracy and commotion can be derived from the error matrix: error of omission, or producer's accuracy, and commission, or user's accuracy of a specific class is the ratio of the correctly classified samples to the total number of samples selected in the class. Likewise, the producer's accuracy of one class is derived by taking the ratio of correctly defined pixels to the total number of pixels selected for that class in the reference data.

For classification purposes, 75 or 100 samples per land-use is recognized acceptable in evaluating large area $\left(\sim 4000 \mathrm{Km}^{2}\right)$ or if there are more than twelve land-use classes in the analysis [20]. After eliminating reference data close to boundaries, 95 samples, completely included within 10 - 15 pixels, were randomly selected from reference stations of each land-use class and given a unique identification number. In a random fashion, 35\% of these identification numbers were used for accuracy assessment, and the remainder was used as training sites. Before carrying out change detection, the accuracy of the land-use/land-cover maps was evaluated at several stages in the processing. Table 1 shows that the overall accuracy of the land-use/land cover maps, with the user and producer accuracy and Kappa coefficients of Egypt sat 2009.

In Egypt due to the presence of water and vegetation cover all the years leads to great difficulties to distinguish between urban areas and agriculture fields because of similar visible-near infrared spectra [4,28]. In my study the calculated overall accuracies represent the maximum obtainable accuracies but not the optimum. This is due to the errors of omission which are calculated from the producer accuracy data not accounting for any possible bias introduced by the details of the sampling process, for example the sampling technique itself or the number of samples per class [29]. Table 1 shows that the agriculture classification accuracy is $94 \%$, while urban classification is $97.56 \%$ and the River Nile classification accuracy is 94.23 .

\section{Change Detection}

Change detection is a general remote sensing technique that compares imagery collected over the same area at different times and highlights features that have changed. Many remote sensing change detection techniques have been developed, and the advantages and disadvantages of each have been reviewed by a number of authors [26]. However, new digital change detection techniques are continuing to be developed, primarily in response to the range of social and environmental challenges posed by human transformation of the Earth's surface [30,31] and the potential of remote sensing in monitoring related processes [32-34].

All change detection techniques rely on the basic idea that changes in the spectral and/or textural characteristics of geometrically, atmospherically, and topographically corrected remotely sensed imagery represent changes of the Earth's surface. The most frequently used change detection algorithms are image differencing, principal components analysis, and post-classification comparison, respectively.

In this study, the post-classification comparison method is the most preferable. The magnitude and location of change ("from-to" change detection matrix) were determined for the entire studied years (1987-2009). The major land cover changes were color coded. Table 2 shows the observed major land cover changes and the area of each land cover class has been given in $\mathrm{m}^{2}$ with the yearly average change in each type (each class).

\section{Discussion and Conclusions}

Understanding the potentiality of natural resources and a natural hazard are very important in the development and

Table 1. User's and producer's accuracies and Kappa coefficients for the change detection data analysis.

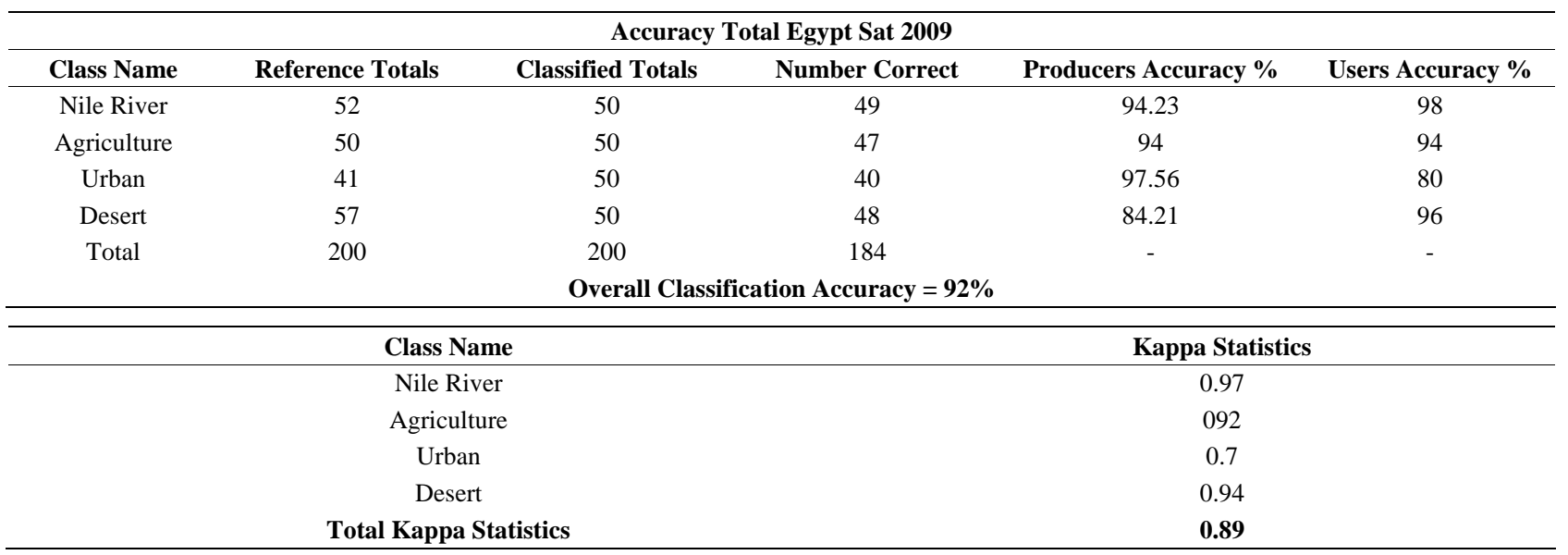


also in the creation of new societies [35].

This information are not only useful to improve the natural resources but also play a vital role in keeping the land development from water logging, soil salinity, desertification and probable natural hazards like Flash floods [36]. The statistics and maps product from the analysis are useful in monitoring socioeconomic potential and trends [4].

The agriculture in the study area covered about 34573.90 ha in 1987 while it reached about 36359.80 ha in 2009 (Figure 5), that means a total increase in the agriculture area from 1987 to 2009 of about 1785.9 ha

Table 2. The lands cover changes in (Hectare) in 1987 and 2009 and the average of Change per year.

\begin{tabular}{cccc}
\hline Class & $\mathbf{1 9 8 7}$ & $\mathbf{2 0 0 9}$ & Total Change \\
\hline Agriculture & 34573.90 ha & 36359.80 ha & 1785.9 ha \\
Urban & 6034.37 ha & 8265.58 ha & 2231.21 ha \\
River Nile & 686.79 ha & 825.11 ha & 138.32 ha
\end{tabular}
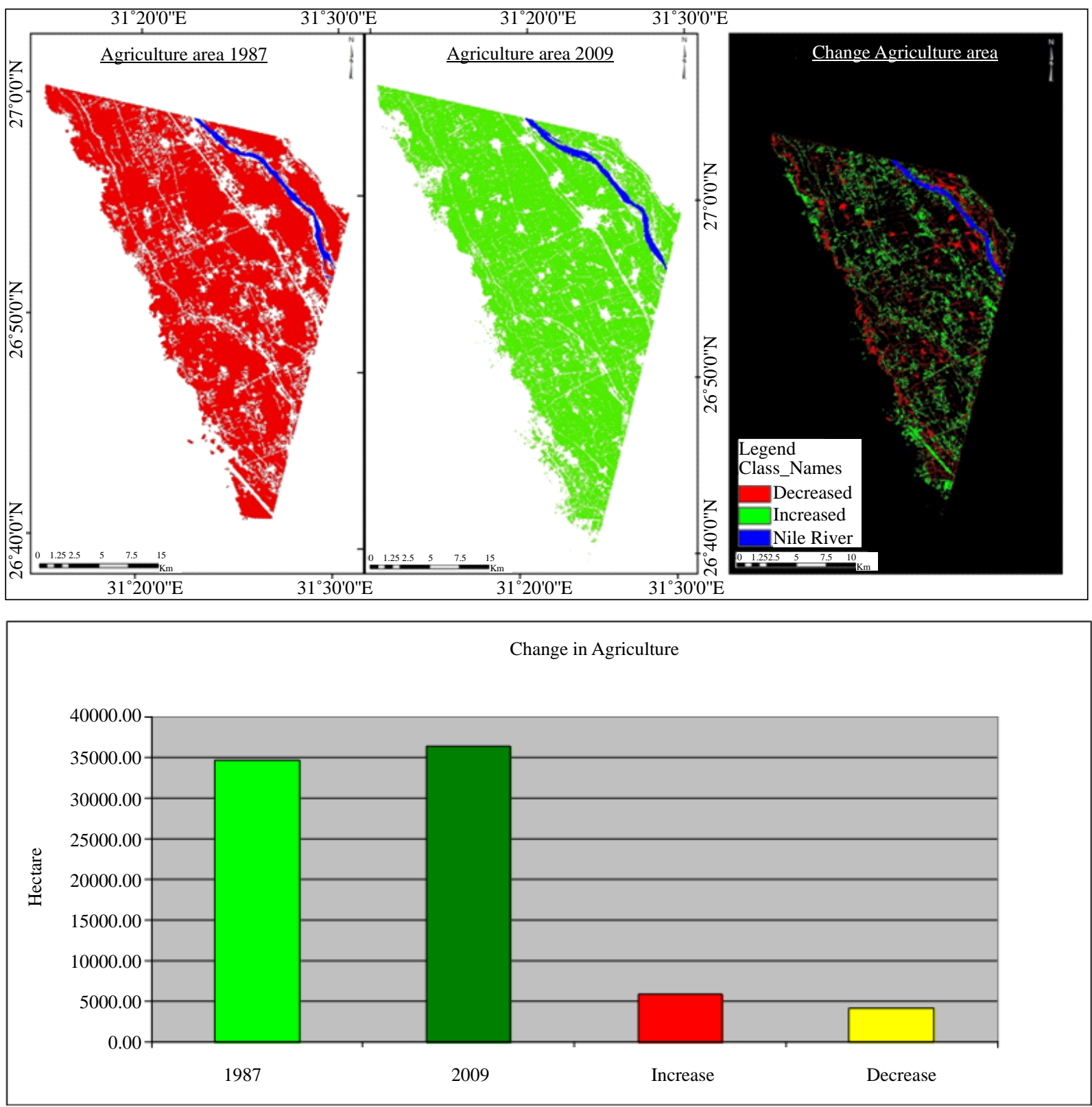

Figure 5. Change detection map in agriculture area. 
with an average annual rate of $81.2 \mathrm{ha} /$ year. This increase in the agriculture area is due to the extensive reclamation project in the study area. Presence of underground water represented by Quaternary aquifer plays an important role in the development. This aquifer mainly recharged from the surface water (River Nile and irrigation canal) this leads to the groundwater suitable for irrigation, due to the low of salinity and also sodium adsorption ratio.

The presence of suitable water for live act as the main role in the development, this leads to extensive urban project to resolve the increasing in population. Figure 6 shows total urban area in 1987 are 6034.37 ha and in 2009 it reached to 8265.58 ha with total increase in the period from 1987 to 2009 about 2231.21 ha and average annual rate $101.45 \mathrm{ha} /$ year.

River Nile is the main source of the surface water in the study and act as the source of the recharge of the quaternary aquifer which also act as the main source of the groundwater in the area under investigation. The River Nile from 1987 to 2009 (Figure 7), in 1987 are covered about 686.79 ha and in 2009, 825.11 ha with total change in this period about 138.32 ha and average annual
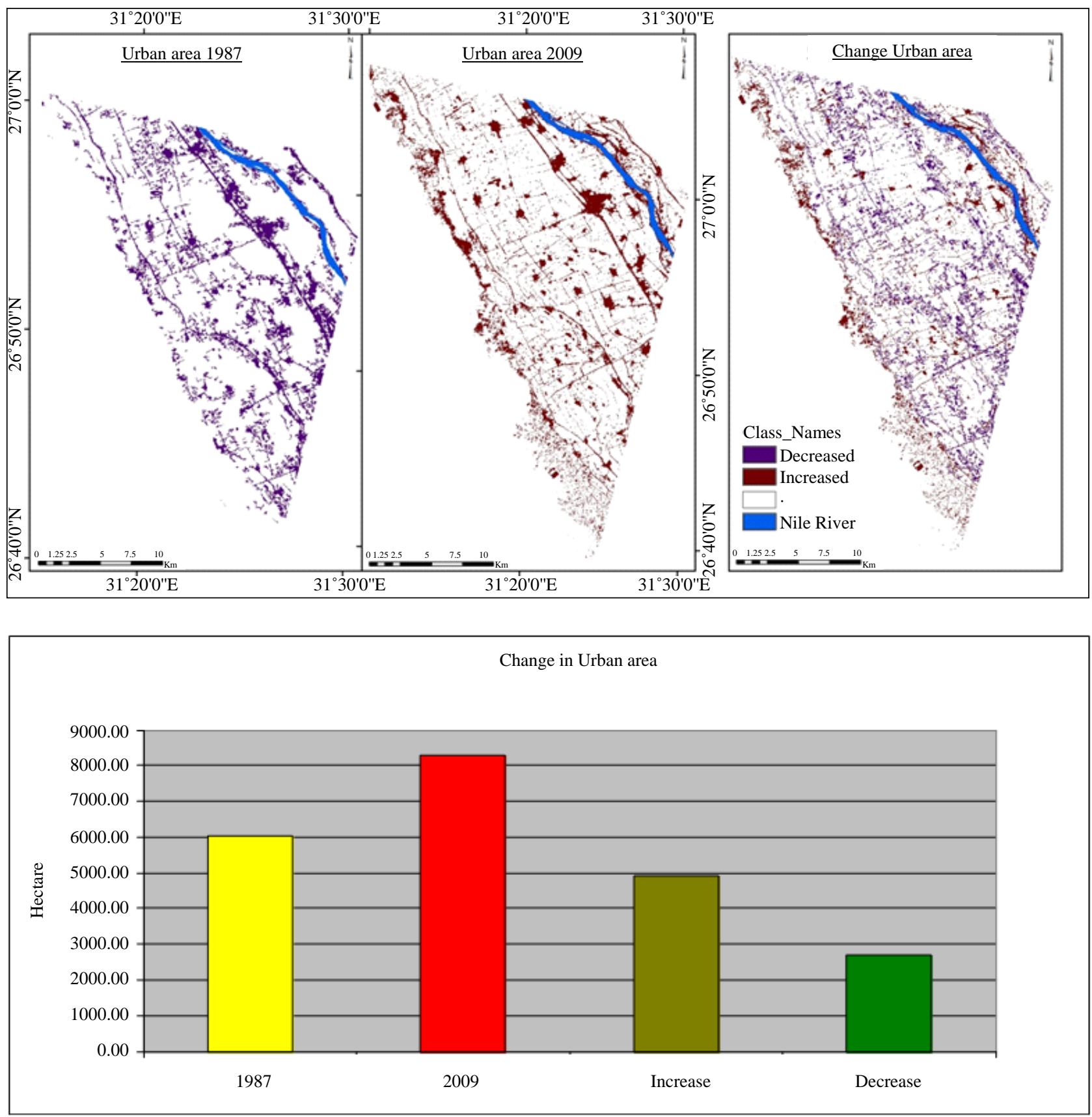

Figure 6. Change detection map in urban area. 

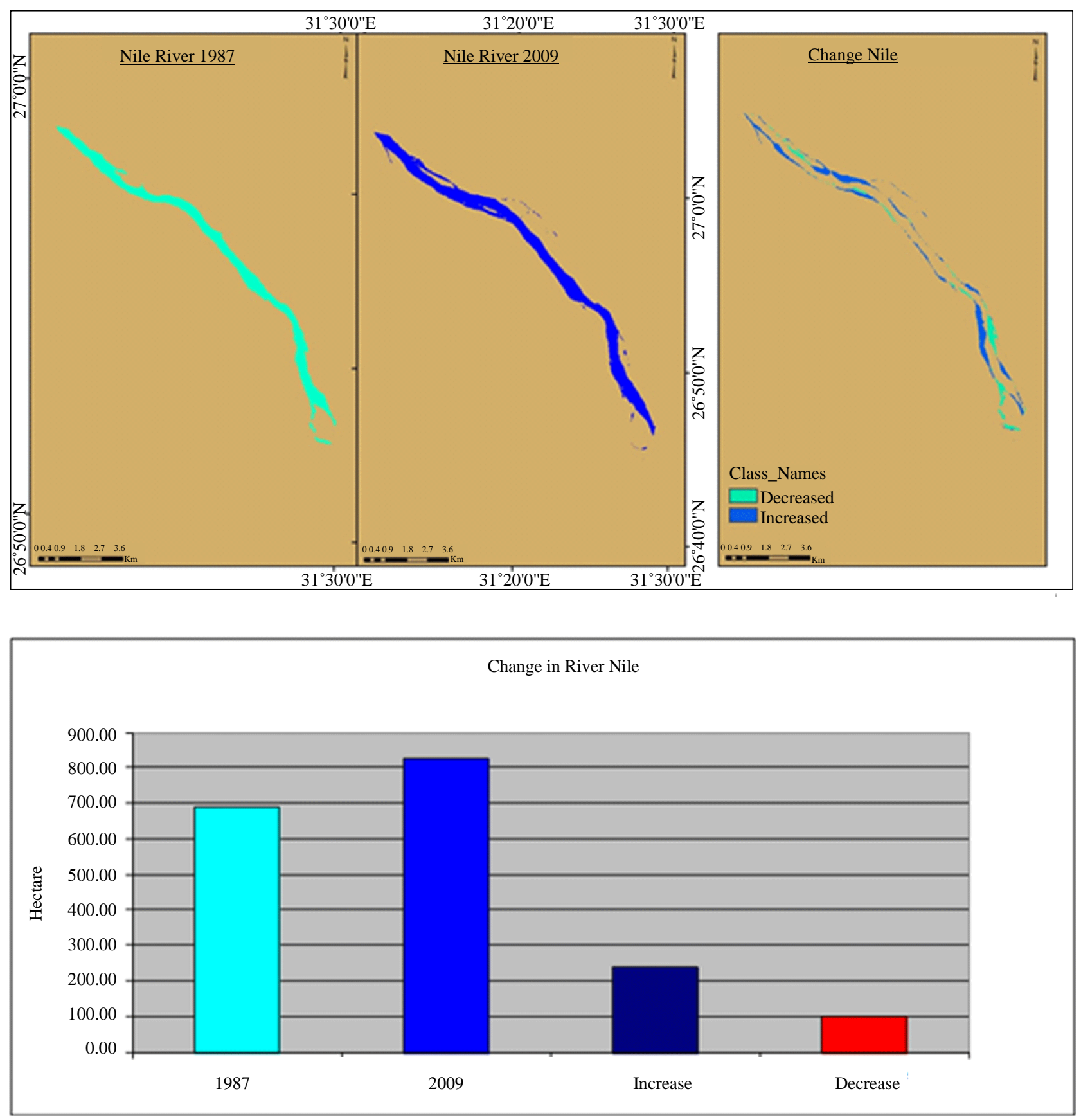

Figure 7. Change detection map in River Nile.

rate $6.29 \mathrm{ha} /$ year.

From the upper discussion we found that, there are high change in the agriculture area and urban area it reached to 81.2 ha/year and 101.45 ha/year respectively. The change in the River Nile is low with average annual rate $6.29 \mathrm{ha} /$ year.

\section{REFERENCES}

[1] Msrintranet.Capmas.gov.eg, "Central Agency for Population Mobilisation and Statistics-Population Clock,” 2011. http://www.msrintranet.capmas.gov.eg/pls/fdl/tst12e?acti on=\&lname

[2] T. H. Brikowski and A. M. Faid, "Pathline-Calibrated Groundwater Flow Models of Nile Valley Aquifers, Esna, Upper Egypt,” Journal of Hydrology, Vol. 324, No. 1-4, 2006, pp. 195-209. doi:10.1016/j.jhydrol.2005.10.011

[3] Food and Agriculture Organization of the United Nations, “FAO Statistical Year Books 2005-2006, Issue 2,” Food and Agriculture Organization of the United Nations, Rome, 2006.

[4] A. M. Abdulaziz, J. M. Hurtado and R. Al-Douri, “Ap- 
plication of Multitemporal Landsat Data to Monitor Land Cover Changes in the Eastern Nile Delta Region, Egypt,” International Journal of Remote Sensing, Vol. 30, No. 11, 2009, pp. 2977-2996. doi:10.1080/01431160802558675

[5] J. R. G. Townshend, "Improved Global Data for Land Applications: A Proposal for a New High Resolution Data Set,” Report No. 20, International Geosphere-Biosphere Program, Stockholm, 1992.

[6] R. S. DeFries and J. R. G. Townshend, “Global Land Cover: Comparison of Ground Based Data Sets to Classifications with AVHRR Data,” Wiley, Chichester, 1994.

[7] J. E. Vogelmann, D. Helder, R. Morfitt, M. J. Choate, J. W. Merchant and H. Bulley, "Effect of Landsat 5 Thematic Mapper and Landsat 7 Enhanced Thematic Mapper Plus Radiometric and Geometric Calibrations and Corrections on Landscape Characterization," Remote Sensing of Environment, Vol. 78, No. 1-2, 2001, pp. 55-70. doi:10.1016/S0034-4257(01)00249-8

[8] K. Green, D. Kempka and L. Lackey, "Using Remote Sensing to Detect and Monitor Land-Cover and Land-Use Change," Photogrammetric Engineering and Remote Sensing, Vol. 60, No. 3, 1994, pp. 331-337.

[9] P. T. Wolter, D. J. Mladenoff, G. E. Host and T. R. Crow, "Improved Forest Classification in the Northern Lake States Using Multitemporal Landsat Imagery," Photogrammetric Engineering and Remote Sensing, Vol. 61, No. 9, 1995, pp. 1129-1143.

[10] R. K. Kaufman and K. C. Seto, "Change Detection, Accuracy, and Bias in a Sequential Analysis of Landsat Imagery in the Pearl River Delta, China: Econometric Techniques," Agriculture, Ecosystems and Environment, Vol. 85, No. 1-3, 2001, pp. 95-105. doi:10.1016/S0167-8809(01)00190-6

[11] F. Yuan, K. E. Sawaya, B. C. Loeffelholz and M. E. Bauer, "Land Covers Classification and Change Analysis of the Twin Cities (Minnesota) Metropolitan Area by multitemporal Landsat Remote Sensing," Remote Sensing of Environment, Vol. 98, No. 2-3, 2005, pp. 317-328. doi:10.1016/j.rse.2005.08.006

[12] L. Geosystems, "Leica Geosystems Geospatial Imaging ERDAS IMAGINE 9.2,” Leica Geosystems Geospatial Imaging, Norcross, 2008.

[13] H. El-Sayed, "Environmental Investigation on Lake Maryut, West of Alexandria, Egypt: Geochemical, Geophysical and Remote Sensing Study,” M.Sc. Thesis, Alexandria University, Alexandria, 2010.

[14] N. Levin, "Fundamentals of Remote Sensing," 1st Hydrographic Data Management Course, IMO-International Maritime Academy, Trieste, 1999.

[15] F. F. Sabins, "Remote Sensing, Principles and Interpretation,” Freeman, New York, 1997.

[16] P. M. Harris and S. J. Ventura, "The Integration of Geographic Data with Remotely Sensed Imagery to Improve Classification in an Urban Area," Photogrammetric Engineering and Remote Sensing, Vol. 61, No. 8, 1995, pp. 993-998.

[17] J. R. Jensen, “Digital Change Detection,” In: Introductory Digital Image Processing-A Remote Sensing Perspec- tive, Pearson Prentice Hall, Upper Saddle River, 2004, pp. 467-494.

[18] G. Rosenfield and K. Fitzpatrick-Lins, "A Coefficient of Agreement as a Measure of Thematic Classification Accuracy,” Photogrammetric Engineering and Remote Sensing, Vol. 52, No. 2, 1986, pp. 223-227.

[19] R. G. Congalton, "A Review of Assessing the Accuracy of Classifications of Remotely Sensed Data," Remote Sensing of Environment, Vol. 37, No. 1, 1991, pp. 35-46. doi:10.1016/0034-4257(91)90048-B

[20] R. G. Congalton and K. Green, "Assessing the Accuracy of Remotely Sensed Data: Principles and Practices," Lewis Publishers, Boca Raton, 1999.

[21] M. Story and R. G. Congalton, “Accuracy Assessment: A User's Perspective,” Photogrammetric Engineering and Remote Sensing, Vol. 52, No. 3, 1986, pp. 397-399.

[22] T. M. Lillesand and R. W. Kiefer, "Remote Sensing and Image Interpretation,” 4th Edition, John Wiley \& Sons, New York, 1994.

[23] J. B. Campbell, "Introduction to Remote Sensing,” 3rd Edition, The Guilford Press, New York, 2002.

[24] W. Hudson and C. Ramm, "Correct Formula of the Kappa Coefficient of Agreement,” Photogrammetric Engineering and Remote Sensing, Vol. 53, No. 4, 1987, pp. 421422.

[25] J. R. Thomlinson, P. V. Bolstad and W. B. Cohen, “Coordinating Methodologies for Scaling Landcover Classifications from Site-Specific to Global: Steps toward Validating Global Map Products," Remote Sensing of Environment, Vol. 70, No. 1, 1999, pp. 16-28.

[26] J. R. Anderson, E. E. Hardy, J. T. Roach and R. E. Witmer, "A Land Use and Land Cover Classification System for Use with Remote Sensor Data-No. Professional Paper 964,” US Geological Survey, Washington DC, 1976.

[27] A. Shalaby and R. Tateishi, "Remote Sensing and GIS for Mapping and Monitoring Land Cover and Land-Use Changes in the Northwestern Coastal Zone of Egypt," Applied Geography, Vol. 27, No. 1, 2007, pp. 28-41. doi:10.1016/j.apgeog.2006.09.004

[28] M. Pax-Lenney, C. E. Woodcock, J. C. Collin and H. Hamdi, "The Status of Agriculture in Egypt: The Use of Multitemporal NDVI Features Derived from Landsat TM,” Remote Sensing of Environment, Vol. 56, No. 1, 1996, pp. 8-20. doi:10.1016/0034-4257(95)00152-2

[29] A. M. Hay, "Sampling Designs to Test Land Use Map Accuracy," Photogrammetric Engineering and Remote Sensing, Vol. 45, No. 4, 1979, pp. 529-533.

[30] A. S. Goudie, "Land Transformation,“ In: R. J. Johnston, Ed., The Challenge for Geography, A Changing World, A Changing Discipline, Black Well, Cambridge, 1993, pp. 17-137.

[31] R. M. Turner, "Long-Term Vegetation Change at a Fully Protected Sonoran Desert Site,” Ecology, Vol. 71, No. 2, 1990, pp. 464-477. doi:10.2307/1940301

[32] G. Gutman, “Land Change Science,” In: Monitoring and Understanding Trajectories of Change on the Earth's Surface, Kluwer Academic Publishers, Dordrecht, 2004, 
pp. 329-350.

[33] COSPAR, International Council of Scientific Unions, "Potential of Remote Sensing for the Study of Global Change: COSPAR Report to the International Council of Scientific Unions (ICSU),” Pergamon Press, Oxford, 1987.

[34] S. Ustin, "Manual of Remote Sensing: Remote Sensing for Natural Resource Management and Environmental Monitoring,” John Wiley and Sons, Chichester, 2004.

[35] N. Bakr, D. C. Weindorf, M. H. Bahnassy, S. M. Marei and M. M. El-Badawi, "Monitoring Land Cover Changes in a Newly Reclaimed Area of Egypt Using Multi-Temporal Landsat Data,” Applied Geography, Vol. 30, No. 4, 2010, pp. 592-605. doi:10.1016/j.apgeog.2009.10.008

[36] M. F. Abdalla and M. A. Abdulaziz, "Monitoring LandUse Change Associated Land Reclamation Using Multitemporal Landsat Data and Geoinformatics in Kom Ombo Area, South Egypt," International Journal of Remote Sensing, 2011. (in Press) 